Volume 8, No. 7, July - August 2017

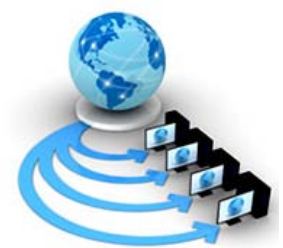

International Journal of Advanced Research in Computer Science

TECHNICAL NOTE

\author{
Available Online at www.ijarcs.info
}

\title{
HEART BEAT MONITORING SYSTEM AND SECURITY USING ANDROID
}

\author{
Bhaskar Niraghatam \\ Research Scholar, \\ Computer Science, Rayalaseema University, \\ Kurnool-518007, \\ Andhra Pradesh, India
}

\author{
M V Ramanamurthy \\ Professor, BOS Chairman, \\ Dept. of Mathematics and Computer Science, \\ Osmania university, Hyderabad-500007, \\ Telangana State, India
}

\author{
R. Sai Bhavani, G Rama Devi \\ Asst. Professor, \\ Dept. of CSE, SVIT, Seunderabad, \\ Telangana State, India
}

\begin{abstract}
This paper is intended to monitor Heart beat with android application which is used to measure the heart beat of different persons. It is built using Android Studio. It may also include the different modules based on the software specification, system requirement, hardware requirement and disk space.
\end{abstract}

Keywords: Heartbeat, Security, Android, patient, analysis

\section{INTRODUCTION}

Heart Rate monitoring is an android application which is used for heart pulse recording of different persons of different age groups. It is mainly built using Android Studio Based on taking pulse and calculates blood pressure [1]. It may also include the different modules based on the software specification. The paper is also observed the security in accessing patient pulse data and maintain multiple patient's data.

\section{Problem Statement}

It is a newly proposed system consists of android application in which heart pulse is taken and expert advice is given. It is mainly helpful in remote areas where immediate medication is not available. It is a newly Proposed System, Which is used to take pulse among different users[6]. It is userFriendly and allows the user to interact with doctor by sharing the pulse.

\section{Problem Analysis}

In the Paper Analysis phase, analyst has to identify the client requirements, and plan an outline for the paper. Analyst has to make discussion with the client and conducts detailed survey of the clients' business. This analysis identifies the nature of business, brand and other business attributes. It also determines the prospective goals and target audience [2].

The analysis should be done in the way, that it may not be too time consuming or very less informative. The team should be able to come up with the complete cost- benefit analysis and as the plan for the paper will be an output of analysis, it should be realistic. To achieve this, analyst should consult the designers, developers and testers to come up with a realistic plan. Output of this phase should include Work plan, Cost involved, Team requirements, hardwaresoftware requirements, supporting documents and the Client approval [ 5 ].

The detailed investigation of the system is carried out in accordance with the objectives of the proposed system. This involves detailed study of various operations performed by a system and their relationships within and outside the system. During this process, data are collected on the available files, decision points and transactions handled by the present system. Interviews, on-site observation and questionnaire are the tools used for detailed system study. Using the following steps it becomes easy to draw the exact boundary of the new system under consideration[3][4]:

Keeping in view the problems and new requirements, it is identified the working of application by considering the pros and cons including new areas of the system. The flow of application and flow of data is depicted in Fig. 1. The elements involved in this paper environment are : User authentication, Patient heart pulse collection, Storage of pulse data at a permanent location for future retrieval. 


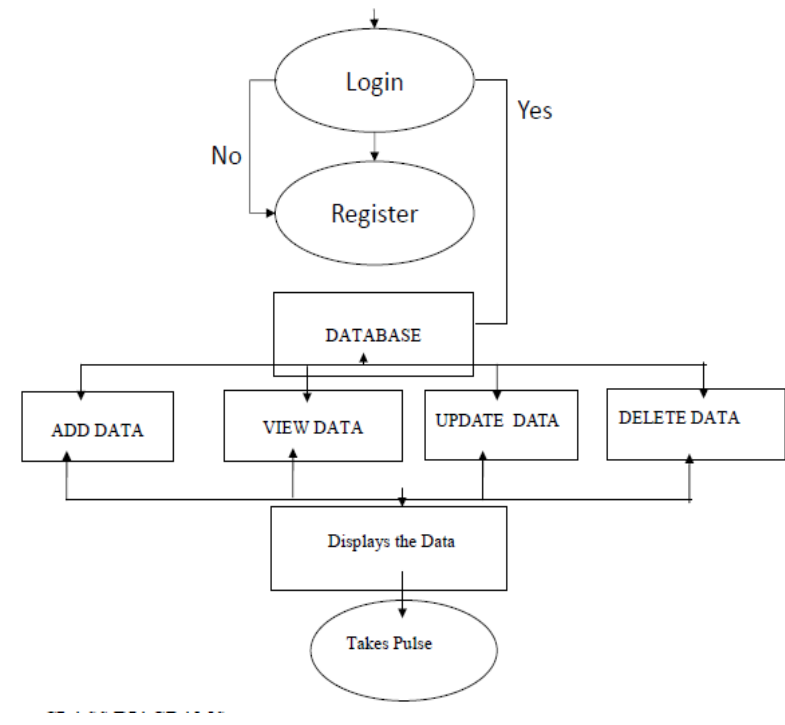

Fig 1. Flow of data for Pulse Rate reading system

\section{KEYWORDS}

APKs: Android App built in themes.

IDE: Integrated Development Environment.

SQLITE : A light weight backend storage platform for small devices.

Pro-guard: It is a free Java class file shrinker, optimizer, obfuscator, and pre-verifier. It detects and removes unused classes, fields, methods, and attributes [8] [10].

\section{TECHNOLOGY BEING ADOPTED}

Android Studio:

Android Studio is the official IDE for Android app development, based on IntelliJ IDEA. On top of IntelliJ's powerful code editor and developer tools, [14][15]Android Studio offers even more features that enhance the productivity while building Android apps, such as:

- A flexible Gradle-based build system

- Build variants and multiple APK file generation

- Code templates to help you build common app features

- A rich layout editor with support for drag and drop theme editing

- $\quad$ Lint tools to catch performance, usability, version compatibility, and other problems

- Code shrinking with ProGuard and resource shrinking with Gradle

- Built-in support for Google Cloud Platform, making it easy to integrate Google Cloud Messaging and App Engine

- $\quad$ Project Structure:

Each application in Android Studio contains one or more modules with source code files and resource files. Android environment provides different types of modules include:

- $\quad$ Android app modules

- Test modules

- Library modules

- App Engine modules

The three types files created during development of application are :
- Manifests: Manifest files.

- Java: Source code files.

- Res: Resource files.

> Gradle Build System:

Android Studio uses Gradle as the foundation of the build system, with more Android-specific capabilities provided by the[16] Android Plugin for Gradle. This build system runs as an integrated tool from the Android Studio menu and independently from the command line [7]. It has the features of the build system to:

- $\quad$ Customize, configure, and extend the build process.

- Create multiple APKs for your app with different features using the same project and modules.

- $\quad$ Reuse code and resources across source sets.

The flexibility of Gradle enables you to achieve all of this without

modifying your app's core source files. To build an Android Studio

project, see Building and Running from Android Studio. To configure custom build settings in an Android Studio project, see Configuring Gradle Builds.

$>$ Debug And Profile Tools:

Android Studio assists in debugging and improving the performance of the code, including inline debugging and performance analysis tools.

Inline debugging: Use inline debugging to enhance your code walk-through in the debugger view with inline verification of references, expressions, and variable values. Inline debug information provides:

- Inline variable values

- Referring objects that reference a selected object

- Method return values

- Lambda and operator expressions

- Tool tip values

To enable inline debugging, in the Debug window we need to select the Settings icon and select the check box to Show the Values In Editor[12] [13].

Memory and CPU Manager: We can more easily monitor the application performance and memory usage by CPU, find de-allocated objects, locate memory leaks, and track the amount of memory the connected device is being used. By executing the application on a device or emulator, we can deploy the application on the Android launch window by clicking on the android tab in the left corner of the runtime window.

Click the Memory or CPU

$>$ Data File Access:

The Android SDK tools, such as Systrace, logcat, and Trace view generate performance and debugging data for detailed application analysis[17].

$>$ MySQL/SQLITE : It is used as back end storage tool. It can store large volume of data and supports the data access from multiple platforms. It is widely used database platform for mobile and small applications of any organizations. This is a secured environment, and prevent the unauthorized user access. 


\section{INTERFACES DEVELOPED}

Interface is the communication medium between system and user. In this paper we used patient's heart beat recording[9][11]. It require the initial login by authorized user for security, making the system ready to receive the pulse by connecting mobile through emulator, start recording the pulse beat in the storage device and use it for future reference or comparing the heart pulse beat of the same patient. Following are the some interfaces provides the user interacting environment[18].

User Login

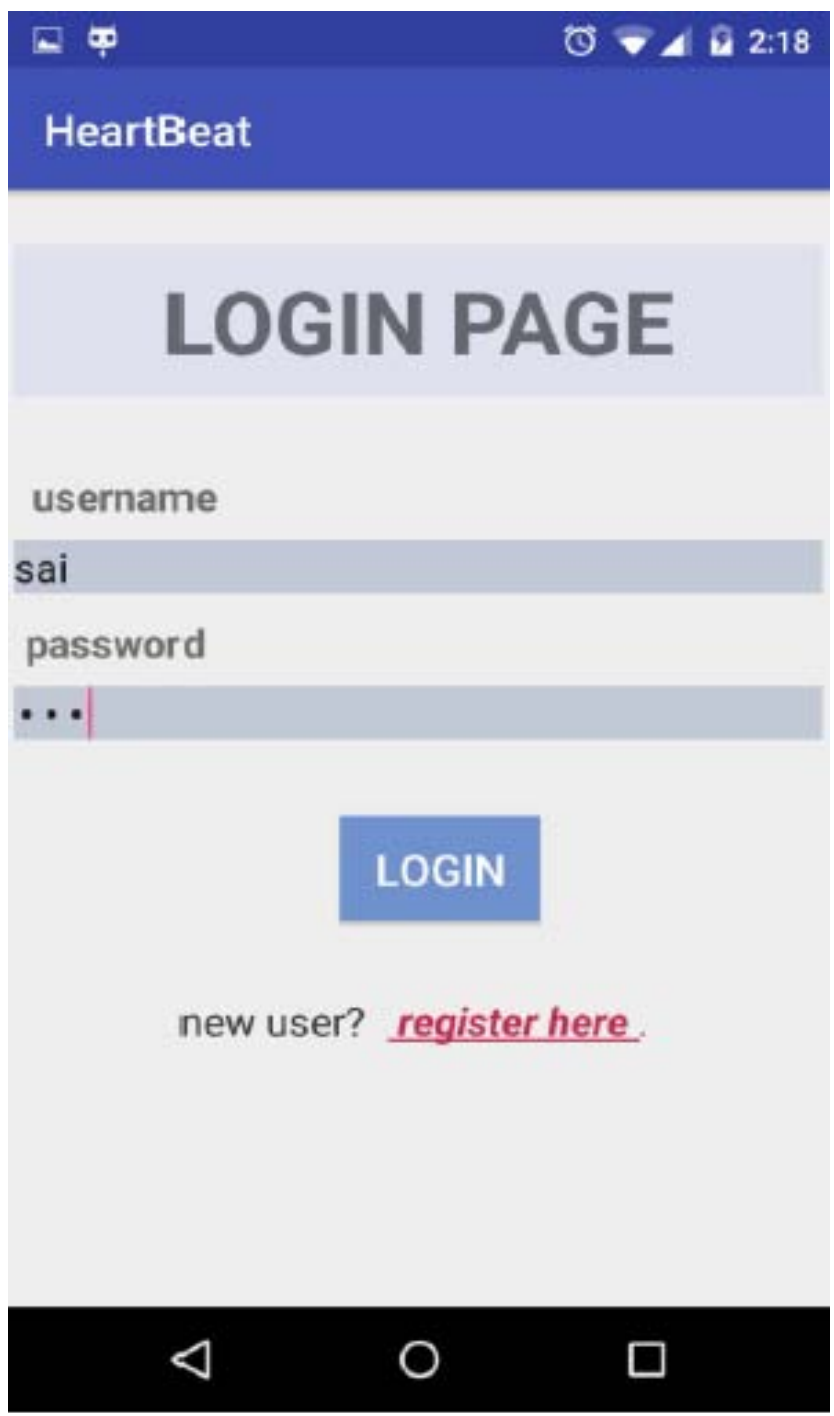

New User Registration

E ए) $12: 16$

\section{REGISTRATION PAGE}

\begin{tabular}{|c|c|c|}
\hline Name & & \\
\hline enter your $\mathrm{r}$ & & \\
\hline Age & & \\
\hline enter your a & & \\
\hline Gender & & \\
\hline give your ge & & \\
\hline Email-id & & \\
\hline email id & & \\
\hline Phone-No & & \\
\hline enter mobil & yer & \\
\hline Password & & \\
\hline enter pa: & & \\
\hline & REGISTER & \\
\hline$\triangleleft$ & 0 & 口 \\
\hline
\end{tabular}

무

ช $>4$ 2:16

Gender

\begin{tabular}{|l|}
\hline female \\
\hline Email-id \\
\hline rajitha@gmail.com \\
\hline Phone-No \\
\hline enter mobile number \\
\hline Password \\
\hline enter password \\
\hline
\end{tabular}

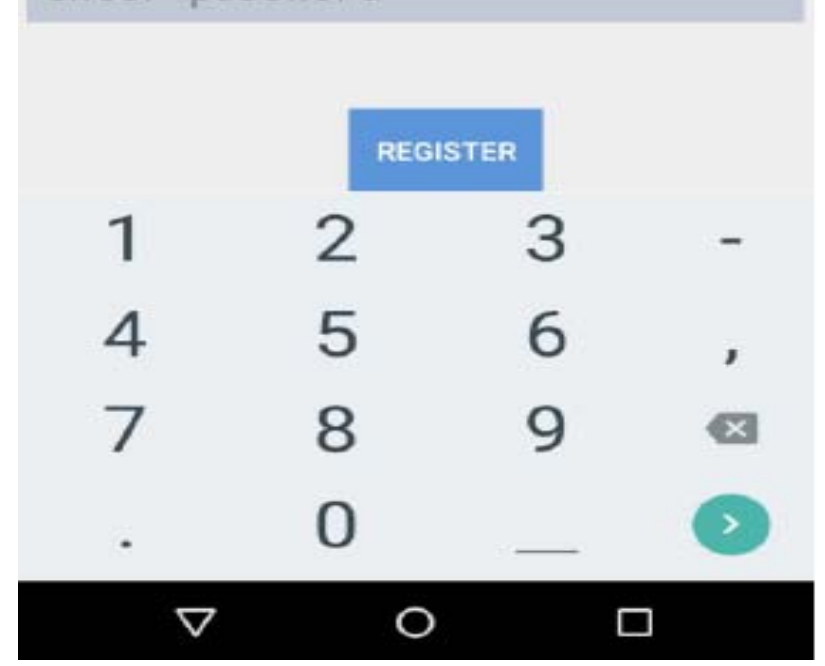


Patient details data entry

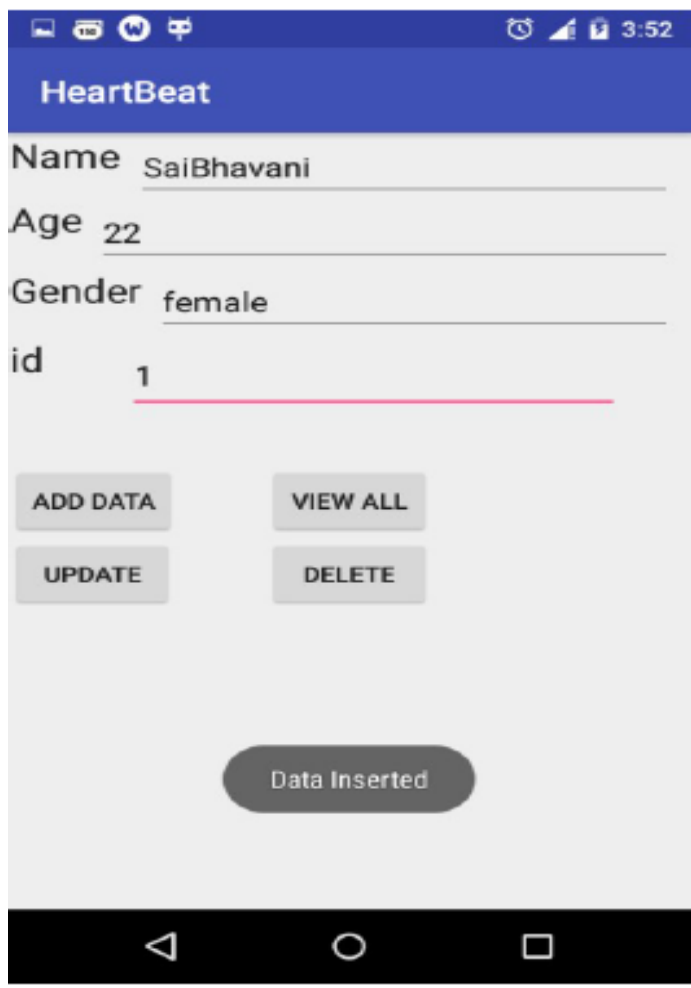

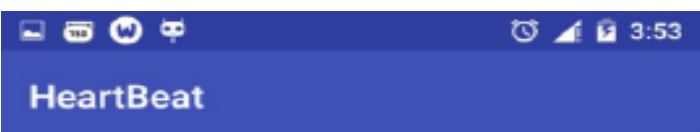

\begin{tabular}{l} 
Name Rajitha \\
Age 23 \\
Gender female \\
id 2 VIEW ALL \\
\hline ADD DATA \\
\hline UPDATE \\
\hline \\
\end{tabular}

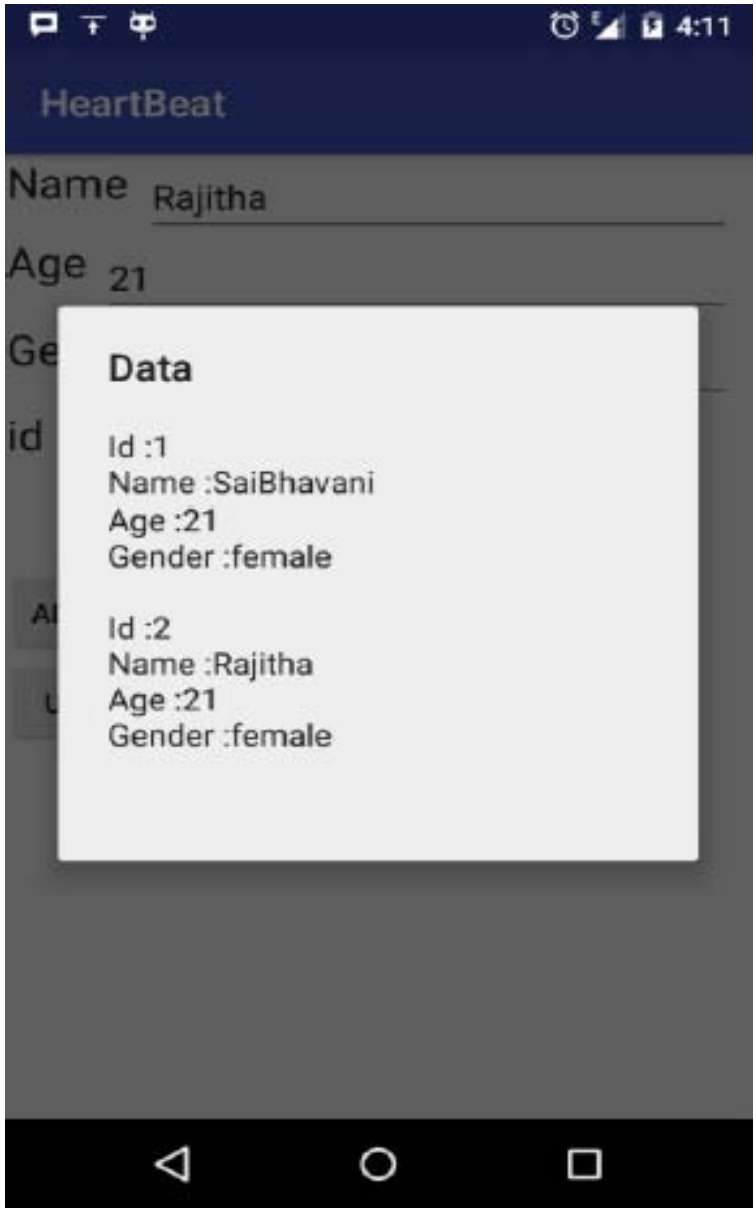

After recording the pulse

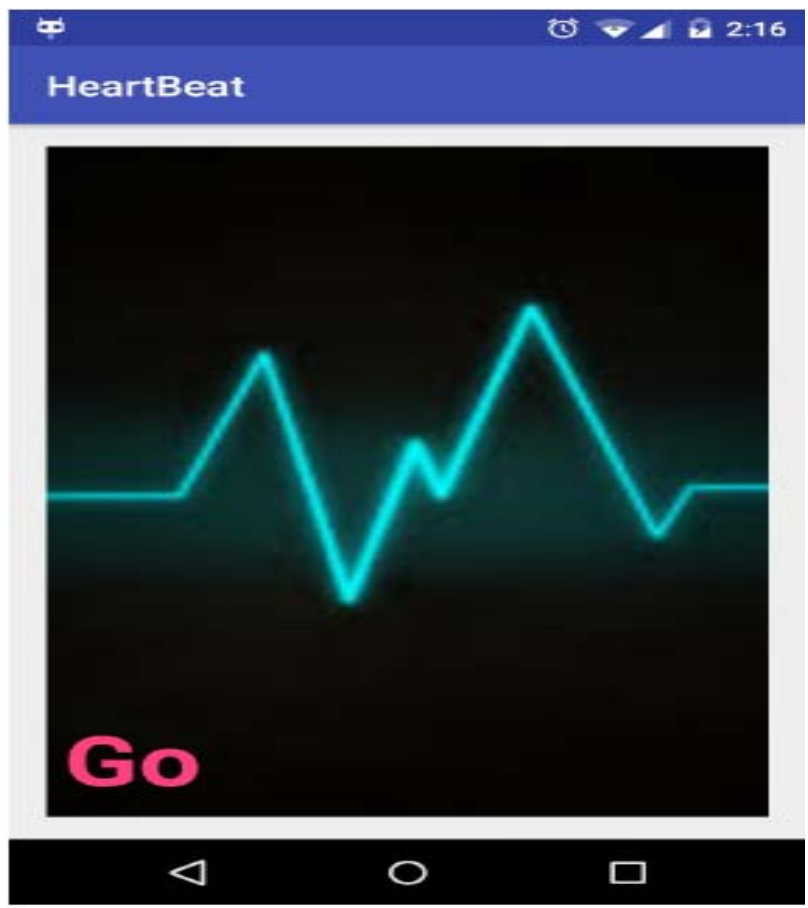




\section{CONCLUSION}

In future it will be available in Play store for free download, and will add other view details of the patient records and will make our server bigger the bugs in the next development. As per the user requirement, it satisfy the basic needs. But this paper can be enhanced in future for image compression and performance enhancement. It can also be considered in future for accessing the patient from remote and distance location for immediate decision on the patient's by comparing present and previously store heart pulse reading.

\section{REFERENCES}

[1] Akshay Singh IMS Engineering College, Sakshi Sharma IMS Engineering College, Shashwat Singh IMS Engineering College- Android Application Development using Android Studio and PHP Framework, International Journal of Computer Applications (0975 - 8887) Recent Trends in Future Prospective in Engineering \& Management Technology 2016.

[2] Dr. Vuda Sreenivasa Rao1, Dr. T. Murali Krishna2, American Journal of Engineering Research (AJER) e-ISSN : 2320-0847 p-ISSN : 2320-0936 Volume-03, Issue-06, pp-20-29, American Journal of Engineering Research (AJER) 2014.

[3] Woubshet B. (2012): Android ECG Application Development. OULU University of Applied Sciences, BSc.

[4] Arshad U., et al.: Exploiting Mobile Computing in Health Care. Department of Computer Science, University College London.Webpage:www.cl.cam.ac.uk/ cm542/papers/iwsawc. pdf [date accessed: Dec 12, 2012]

[5] Robert Sowah, Joana nkrumah-buadu and Seth y. fiawoo "design and development of a personal health Monitoring system on android mobile platform”, International Journal of Engineering Science and Technology (IJEST), Vol. 5 No.06 June 2013, 1313-1320.

[6] Zaid A. Habash1, Wan Hussain Wan Ishak2, and Mohd. Hasbullah Omar, ANDROID-BASED APPLICATION TO ASSIST DOCTOR WITH ALZHEIMER'S PATIENT, Proceedings of the 4 th International Conference on Computing and Informatics, ICOCI 2013 28-30 August, 2013 Sarawak, Malaysia. Universiti Utara Malaysia

[7] Deepti Ameta, Kalpana Mudaliar and Palak Patel, MEDICATION REMINDER AND HEALTHCARE - AN ANDROID APPLICATION, International Journal of Managing Public Sector Information and Communication Technologies (IJMPICT) Vol. 6, No. 2, June 2015.

[8] Zao, J.K., Wang, M.Y., Peihsuan, T. and Liu, J.W.S., (2010) "Smart Phone Based Medicine In-take Scheduler, Reminder and Monitor", IEEE e-Health Networking Applications and Services (Healthcom), pp 162 - 168.

[9] Park, KeeHyun \& Lim, SeungHyeon, (2012) "Construction of a Medication Reminder Synchronization System based on Data Synchronization”, International Journal of Bio-Science and Bio-Technology, Vol.4, No. 4, pp1-10.

[10] Suraj Singh1 , Prathamesh Khadamkar2 , Mukesh Kumar3\&Vivek Maramwar, Healthcare Services Using Android Devices, The International Journal Of Engineering And Science (IJES) || Volume || 3 || Issue || 4 || Pages || 41-45 || 2014 || ISSN (e): 2319 - 1813 ISSN (p): 2319 - 1805.

[11] Francois Andry, Lin Wan and Daren Nicholson(2011),” A Mobile Application Accessing patient's Health Records Through A Rest API how REST-Style Architecture can Help Speed up the Development of "Mobile Health Care Applications".

[12] Daryl Abel, Bulou Gavidi, Nicholas Rollings and Rohitash Chandra, Development of an Android Application for an Electronic Medical Record System in an Outpatient Environment for Healthcare in Fiji, TECHNICAL REPORT, AICRG, SOFTWARE FOUNDATION, FIJI, MARCH 2015.

[13] E.M. Meslin, S.A. Alpert, A.E. Carroll, J.D. Odell, W.M. Tierney, P.H. Schwartz, Giving patients granular control of personal health information: Using an ethics Points to Consider to inform informatics systems designers, International journal of medical informatics , vol. 82, pp. 1136-1143, Aug 2013.

[14] S. Reis, D. Sagi, O. Eisenberg, Y. Kuchnir, J. Azuri, V. Shalev, A. Ziv, "The impact of residents training in Electronic Medical Record (EMR) use on their competence: Report of a pragmatic trial, Patient Education and Counseling, vol. 93, pp. 515-521, Aug 2013.

[15] Mayuri Navale1 ,Sandhya Damare2 , Rameshwari Chavan3 , Renuka Dube4, Prof. Suhas Patil5, Android Based Heart Monitoring and Reporting System, International Journal of Advanced Research in Computer and Communication Engineering Vol. 3, Issue 5, May 2014.

[16] Gipsa Alex1 , Benitta Varghese2 , Jezna G Jose3 , AlbyMol Abraham4, A Modern Health Care System Using IoT and Android, Gipsa Alex et al. / International Journal on Computer Science and Engineering (IJCSE), 2014.

[17] Geng Yang, Li Xie, Matti Mäntysalo, Xiaolin Zhou,Zhibo Pang, Li Da Xu, Senior,Sharon Kao-Walter, Qiang Chen, and Li-Rong Zheng, "A Health-IoT Platform Based on the Integration of Intelligent Packaging, Unobtrusive Bio-Sensor, and Intelligent Medicine Box,” IEEE Transaction Industrial Informatics, vol. 10, no. 4, november 2014.

[18] A. J. Jara, M. A. Zamora-Izquierdo, and A. F. Skarmeta, "Interconnection framework for m-health and remote monitoring based on the Internet of Things,” IEEE J. Sel. Areas Commun., vol. 31, no. 9, pp. 47-65, Sep. 2013. 